\title{
Use of Multimedia Learning Technology Based Graphical User Interface (GUI)
}

\author{
Chandra Anugrah Putra \\ Muhammadiyah University of Palangkaraya \\ Jl. RTA. Milono, Km. 1,5 Palangka Raya 73111, Indonesia \\ chandra.anugrah@umpalangkaraya.ac.id
}

\begin{abstract}
Recently, teachers have various problems when implementing the learning in the classroom. Learning problems are caused because the teachers do not understand the characteristics of learners with learning content. Multimedia as a new product of modern technology seeks to involve all the senses, including visual, hearing and feeling. The purpose of this study is multimedia can compare with other educational media, multimedia tools and methods are used to create good communication between teachers and learners during the learning process. Multimedia can improve attitudes, motivation and imagination of the students in the learning process. Data was analyzed using Analysis of Variance (ANOVA) 2 way design with treatment by level $2 \times 2$. The results showed that: (1) there are significant multimedia design to learning outcome; (2) there is the influence of visual spatial intelligence to multimedia design.
\end{abstract} $(G \boldsymbol{U I})$

Keywords - Multimedia, Learning, Graphical User Interface

\section{INTRODUCTION}

Technology has crept into various domains, both the realm of social, political, information, education, and so forth. But over time, the public is also continuously equip and renew its technological knowledge by learning how to make some of these technologies. The electronics revolution cannot be denied, became one of the causes of changing styles and patterns of human life today. Technology, which is the visual embodiment of operating the digital world has developed so rapidly. The count is no longer in a number of years, months or days, but in seconds. Technology is integral and indispensable to the life of modern society. Toffler in Miarso (2004) described the development as a revolution that took place in three waves. The first wave in the form of agricultural technology, the second wave is characterized by the technology industry, and the third wave of the revolution of electronics and informatics technology.

The learner is now not only design a good learning content, but also pay attention to how the learning content can be well also to students. That is because not all of the learning content can be understood by students if only conveyed through stories, pictures in a textbook, or a method of delivering conventional as usual, for example in a process of how the volcanoes erupted, illustrations electrical engineering or electrical engineering, animal habitats, and so forth. Utilization of multimedia-based learning media will be able to help the innovators in the field of education is the creation of their brilliant ideas, not only on improving the quality of education, but also on understanding the learners in receiving the knowledge of the subjects who had been given. This leads to delivery technique or presentation of the Teacher or Lecturer associated with learning content that will be delivered to the learners.

The development of educational technology can also support media making quality learning so as to reinforce students understanding of the concepts being taught, and may increase the interest of learners. Media serves as a learning tool in the learning activities in the form of facilities that can provide a visual experience to students in order to encourage motivation to learn, clarify and simplify the complex and abstract concepts become more simple, concrete and easy to understand. So the media can serve to enhance absorption and retention of learners towards learning materials.

Smaldino, et al., (2007) suggest that technology plays an important role in the education of students invariably. Utilizing and designing technology and media in particular can make a major contribution to effective learning in all students and help them reach their highest potential regardless of their innate abilities. Computer as one of the technologies considered appropriate product is used as a learning tool and has huge potential to be used in the learning process. Computers capable of displaying a variety of media components called with multimedia, such as video, images, text, animation, and sound so it can stimulate more senses.

Suyanto (2005) states that multimedia is the use of computers to create and combine texts, graphics, audio, moving images (video and animation) by combining links and tools that allow users to navigate, interact, trying creations, and communicate. Furthermore, Vaughan (2006) says that multimedia is a combination of text, art, sound, animation and video delivered to an audience with a computer or electronic equipment and digital manipulation of others. Through a combination of these media into interactive learning experiences that reflect an experience in everyday life. Munir (2008), that can be interpreted as a multimedia presentation technology that optimizes the computer's role as a medium that display text, sound, graphics, video, animation in an integrated and interactive display. Multimedia has several features that are not owned by other media. 
In the development of multimedia can be categorized into two groups, namely linear multimedia and interactive multimedia. Linear Multimedia is a multimedia that is not equipped with a controller thereof. Sequential or sequential nature and duration of impressions can be measured. Film and television are included in this group. While a multimedia interactive multimedia is equipped with a controller that can be operated by the user, so the user can choose what you want for the next process. Typically, multimedia is equipped with several navigation which is also called graphical user interface (GUI), either an icon or button, pop-up menus, scroll bars, and others that can be operated by the user for a means of browsing to a wide range of information window with the help means of hyperlinks. Application of interactive multimedia is obtained on learning multimedia and gaming applications. Interactive multimedia does not have a long duration for the broadcast depends on how long the user to browse this media.

Multimedia interactive learning can be applied in education. Multimedia applications in these fields change conventional learning process becomes more interesting and interactive, so that the learning process is not too monotonous as long as this is done in schools in general. Examples such as multimedia applications to improve reading skills in children children. The application can be inserted animations are certainly interesting for the children so that they can help increase their interest in reading and other matters (Vaughan, 2004).

\section{GRAPHICAL USER INTERFACE}

Sawyer and Williams (2003) to express opinions on the following GUI: Graphical User Interface (GUI), the which allows you to use a mouse or keystrokes to select icons (little symbols) and commands from menus (list of activities). They explained that the GUI allows us to use the mouse and keyboard to select icon (small emblem) and a command from the menu (list of activities). Irawan (2009) also gave the same opinion about the GUI or the "graphical interface", the view that allows us to use the mouse to interact on an operating system or application. Valacich and Schneider (2012) explains that users can take advantage of the graphical user interface (GUI) in a visual programming. For example, users can easily give a command button to the display using a computer mouse.

Furthermore, O'Bannon and Puckett (2010) provides an explanation ... a graphic user interface that Allows icons (small graphics) to represent the tools for the system and uses a mouse to move about. They say that the graphic user interface allows the icons (small pictures) to represent a tool that serves the system and move it using a mouse. Opinion - the above opinion expressed in the ease of a GUI to enable or use functions functionality in a software application, just use the mouse and keyboard on the computer to activate the icon (small emblem) and the menu selection activities that have been available.

The quote above is very clear that with a Graphical User Interface (GUI) the user or the user can view the functions functions that are available on the applications used, therefore animation developers simply by activating or using function the function to obtain a form of display or component desired. It is highly relevant to the concept of the previous chapter that describes a WYSIWYG (What You See Is What You Get) which means that what you see is what you will get.

Researchers found a slightly different opinion about the graphical user interface (GUI) by Latham, Crockett, McLean, and Edmonds (2010) in the Proceedings of the International Conference 2010, describes the Graphical User Interface (GUI) as follows: The graphical user interface (GUI) displays Provides a canvas roomates instructions, displays questionnaires, tests, images, documents, interactive movies and the chat area used to send communication to and from the user. The above quotation explains that the Graphical User Interface displays an animation page that provides a command - a command, questionnaires, tests, pictures, documents, films and interactive chat feature that is used to communicate between users.

Overall, in the opinion - opinions above about design techniques Graphical User Interface (GUI), that the Graphical User Interface (GUI) is an interface to enable the user or the user to select a command that will be used, run the program, view a series of files and choose another option is simply to enable or clicking the small picture emblem commonly called the icon using the mouse or keyboard, but it can also through the menu list of activities that have been available on the computer screen or application software used them.

\section{MULTIMEDIA LEARNING BASED GRAPHICAL USER INTERFACE}

Multimedia learning can be classified into three characteristics. First, multimedia is used as one element in the classroom. For example, if the teacher explains the material through teaching in the classroom or on the basis of a reference book, the multimedia is used as a complementary medium to explain the material taught in class. Multimedia with this type is also called the 'presentation of learning'. The material displayed is not too complex and only displays a few items that are considered important, either in the form of text, images, video or animation. Exercises and tests are less suitable to be placed on the presentation of this study, unless the quiz is to build a classroom atmosphere to make it more dynamic.

Second, multimedia is used as a self-learning materials. In this second type of multimedia may be able to support learning in the classroom may not. Unlike the first type, the second type throughout the instructional needs of users satisfied entirely in the multimedia package. That is the entire facility for learning, including training, feedback and tests which support the learning objectives are provided in the package. Third, multimedia is used as a medium only in learning. Thus the entire learning facilities that support learning objectives have also been provided in this package. Such packages are often called CBL (Computer Based Learning).

Bates (1995) emphasized that among other media, multimedia interactivity or other computer-based media is the most obvious (overt). Real interactivity here is interactivity that involves physical and mental from users when trying to program multimedia. For comparison a book or television media actually provide interactivity, only this interactivity are vague (covert) because it only involves mental user. 
Physical interactivity in multimedia learning vary from the most simple to the most complex. Interactivity simple example, pressing the keyboard or click with the mouse to move the page (display) or enter answers of an exercise given by the computer. Interactivity is a complex example of activity in a simple simulation in which the user can vary a particular variable or in a complex simulation in which the user moves a joystick to simulate the movement of aircraft piloting.

Multimedia excellence in this media interactivity is inherently capable of forcing the user to interact with the material both physically and mentally. The ability of this force depends on how effective instruction are able to attract users to try out actively learning presented. An example is a multimedia learning program which contains material about the atom. By using the learning multimedia users will be invited to directly try and use atomic simulations available. By contrast, if the same material is presented with a book or video. In this case the user simply passive (physical) see how to use the atomic displayed. Mental activity (users absorb how to use and set up may occur but physical activity (in this case to try for themselves how to regulate not happen. Put something else - in terms of a simulation - using learning multimedia users will try directly to how things happen.

\section{RESEARCH AND METHODS}

This study uses a quasi-experimental method with 2 way ANOVA design treatment by the level of $2 \times 2$. The research variables consisted of: (1) The dependent variable is the learning outcome of multimedia design; (2) the independent variable is the variable treatment that multimedia designing consisting of A1: graphical user interface (GUI), A2: programming language (PL); and (3) the visual spatial intelligence.

The research sample is set on a course that follows the class multimedia that consists of two classes through simple random sampling technique. The number of students in the experimental class $(\mathrm{A} 1=22)$ and control group $(\mathrm{A} 2=19)$.
TABLE I. MULTIMEDIA DESIGNING COMPETENCE

\begin{tabular}{|c|c|c|c|c|}
\hline \multirow{2}{*}{\multicolumn{2}{|c|}{$\begin{array}{c}\text { Intelligence } \\
\text { Visual Spatial (B) }\end{array}$}} & \multicolumn{2}{|c|}{ Multimedia Design (A) } & \multirow{2}{*}{$\sum$} \\
\hline & & GUI (A1) & PL (A2) & \\
\hline & & $\mathbf{Y i}$ & $\mathbf{Y i}$ & $\mathbf{Y i}$ \\
\hline \multirow{7}{*}{ High (B1) } & $\mathrm{n}$ & 10 & 13 & 23 \\
\hline & $\overline{\mathrm{Y}}$ & 87.00 & 76.46 & 79.13 \\
\hline & SD & 9.25 & 6.69 & 8.86 \\
\hline & Modus & 92 & 70 & 74 \\
\hline & Median & 91 & 74 & 78 \\
\hline & Min & 68 & 68 & 66 \\
\hline & Max & 96 & 88 & 96 \\
\hline \multirow{7}{*}{ Low (B2) } & $\mathrm{n}$ & 12 & 6 & 18 \\
\hline & $\overline{\mathrm{Y}}$ & 75.17 & 76.33 & 74.88 \\
\hline & SD & 9.78 & 5.43 & 7.60 \\
\hline & Modus & 80 & 76 & 74 \\
\hline & Median & 78 & 76 & 75 \\
\hline & Min & 58 & 68 & 58 \\
\hline & Max & 88 & 84 & 88 \\
\hline \multirow{7}{*}{$\sum$} & $\mathrm{n}$ & 22 & 19 & 41 \\
\hline & $\bar{Y}$ & 80.55 & 76.42 & 77 \\
\hline & SD & 11.10 & 6.17 & 8.46 \\
\hline & Modus & 80 & 74 & 74 \\
\hline & Median & 80 & 76 & 76 \\
\hline & Min & 58 & 68 & 58 \\
\hline & Max & 96 & 88 & 96 \\
\hline
\end{tabular}

See the test results animation project is the acquisition of learning outcomes multimedia design students who use the graphical user interface (GUI), highest score of 96, the lowest score 58, the average score of 80.55, standard deviation 11:10, with a mode of 80 , and the median 80 . See the test results animation project is the acquisition of learning outcomes multimedia design students who use the programming language (PL), the highest score of 88 , the lowest score of 68 , the average score of 76.42 , standard deviation of $6: 17$, with a mode of 74 and a median of 76 . Looking at the test results of a animation project is the acquisition of learning outcomes multimedia design students who have visual spatial intelligence is high, the highest score of 96 , the lowest score of 66 , the average score of 79.13 , standard deviation of 8.86 , with 74 modes, and the median 78 . Viewing test results animation project is the acquisition of learning outcomes multimedia design students who have visual spatial intelligence is low, the highest score of 88 , the lowest score 58 , the average score of 74.88 , standard deviation of 7.60 , with 74 mode, and median 75. 
CALCULATION RESULTS OF ANOVA

\begin{tabular}{|l|l|l|l|l|l|}
\hline \multirow{2}{*}{ Sumber } & \multirow{2}{*}{ JK } & \multirow{2}{*}{ Db } & \multirow{2}{*}{ RJK } & \multirow{2}{*}{ Fo } & \multicolumn{1}{|c|}{ F $_{\mathbf{t}}$} \\
\cline { 1 - 4 } Varians & & & & & $\boldsymbol{\alpha}=\mathbf{0 . 0 5}$ \\
\hline Antar A & 478.09 & 2 & 239.04 & 4.24 & 3.16 \\
\hline Antar B & 289 & 1 & 289.00 & 5.13 & 4.01 \\
\hline $\begin{array}{l}\text { Interaksi } \\
\text { AB }\end{array}$ & 475.13 & 2 & 237.56 & 4.21 & 3.16 \\
\hline D & 3269.79 & 58 & 56.38 & - & - \\
\hline Total & 4512 & 63 & - & - & - \\
\hline
\end{tabular}

Based on the results of ANOVA calculation can be seen in the source of variance between A which indicates that the value of $\mathrm{F}=4.24$ is greater than the $\mathrm{F}$ table $=3.16(58: 2)$ at significance level $\alpha=0.05$; then the null hypothesis is rejected. These results apply to the variance as a whole of between A (A1 and A2), so there are differences in learning outcomes competency of multimedia designing between groups of students who use the multimedia design graphical user interface (A1) with a group of students who use the strategy of project base learning design of programming language (A2).

Many research results to improve learning through multimedia such as Wahyudin - Sutikno, A. Isa. The results showed that the students' understanding increased from $60 \%$ of students who otherwise may not understand on to $25 \%$ of students who otherwise may not understand. The results of the analysis of the responses of students to teaching gained the average - average student responses before the action amounted to $72.90 \%$. After the action, value - average student responses increased to $76.81 \%$. Another study conducted by Wafik Khoiri, Rochmad Rochmad, Adi Nur Cahyono. The research results obtained problem solving ability of students learning with multimediat elah achieve classical completeness. The average results of tests students' ability to think creatively learning with multimedia is better than the results of the test's ability to think creatively control class.

In the presentation, multimedia learning can be grouped into several formats, among others; a) tutorial is done tutorial material, as befits a tutorial conducted by the teacher or instructor. Information is done with text, images, whether still or moving. Finished presenting the impression, given a series of questions to evaluate the success rate. b) Drill and Practice is to train the user so as to have proficiency in a skill or strengthen mastery of a concept. c) Simulation of trying to match the dynamic processes that occur in the real world, for example to simulate the aircraft, as if the user performed the activity fly an airplane. This format tries to give real-world experience problems that are usually associated with a risk, such as the aircraft is dropped. d) Experiments or experiments that this format is similar to the simulation, but more aimed at the activities of the experiment, such as lab activities in the science lab, biology or chemistry. Users are expected to eventually be able to explain a concept or phenomenon based on experiments they do are virtual. e) The game is a game that served still refer to the learning process and the program is expected to occur multimedia format playful learning activities.

\section{CONCLUDING REMARKS}

Results of the study group of students taught using the multimedia design graphical user interface (GUI) higher compared with group learning results of students taught using multimedia design programming language (PL).

Learning outcomes competences multimedia designing in the group of students who use the multimedia design graphical user interface (GUI) and intelligent visual spatial higher than the group of students who use the multimedia design of programming language (PL) and has the intelligence visual spatial high.

Learning outcomes competences multimedia designing in the group of students who use the multimedia design graphical user interface (GUI) and intelligent visual spatial lower than the group of students who use the multimedia design of programming language (PL) and has the visual spatial low.

The existence of multimedia as a form of technological progress provides much convenience in the activities studies. The facilities this modern technology, learning becomes easier and more enjoyable. To master the material, students should learn in the classroom, assisted by educators. They can be studied independently by utilizing a wide range of existing multimedia like a) Tutorial b) Drill and Practice c) Simulation d) Trial or Experimental e) Games. Various facilities is expected to increase learning over the years.

\section{REFERENCES}

[1] Bates, A.W.T. (1995), Technology of Open Learning And Distance Education, New York, Tj Press Ltd.

[2] Irawan, (2009). Dictionary of Computers For The Layman's Terms. Palembang: Maxikom.

[3] Latham, Annabel. Keeley Crockett, David Mclean, Dan Bruce Edmonds In Proceedings of International Conference In Shanghai, China, December 2010, Advances In Web-Based Learning Icwl 2010. Berlin: Springer,. E-Book.

[4] Miarso, Yusufhadi. (2004). Sowing Seeds Technology Education. Jakarta: Prenada Media.

[5] Munir. (2008). Curriculum-Based Information and Communications Technology. Bandung: Alfabeta.

[6] O'Bannon, Blanche W. And Kathleen Puckett, (2010) Preparing To Use Technology: A Practical Guide To Curriculum Integration. Boston: Pearson.

[7] Sawyer, Stacey and Brian Williams, (2003), Using Information Technology. New York: Mcgraw-Hill.

[8] [8] Sharon, Smaldino, E, et al, (2011). Learning Technology And Media For Learning, Translated By Arif Rahman From Istrukturional Technology And Media For Learning, Jakarta: Kencana Prenada Media Group.

[9] Suyanto, M. (2005), Multimedia Tools To Increase Competitive Advantage, Yogyakarta: Andi.

[10] Valacich, Joe and Christoph Schneider, (2012), Information Systems Today: Managing In The Digital World. London: Pearson.

[11] Vaughan, Tay. (2006). Multimedia Making It Work Edition 6. Yogyakarta: Andi Offset.

[12] Vaughan, Tay., (2004), Multimedia: Making It Work, Sixth Edition, Mcgraw-Hill Technology Education. 
[13] Wafik Khoiri, Rochmad Rochmad, Adi Nur Cahyono Problem Based Learning Multimedia Assisted In Mathematics Learning Ability To Enhance Creative Thinking. Unnes Journalmathematic Education. Vol 2, No 12013.

[14] Wahyudin, Sutikno, Dan A. Isa. 2010. Multimedia Assisted Learning Effectiveness Using Guided Inquiry Method To Improve Student Interests And Understanding. Journal of Physical Education, Vol. 6,,5862 